\title{
Analysis on Development Strategy of China's Commercial Street: A Case Study of Hangzhou City
}

\author{
HE Zheng-biao \\ Hangzhou Bureau of Economy and Trade, Hangzhou, China \\ Zhejiang Administration of Work Safety, Hangzhou, China
}

\begin{abstract}
China is arranging a boom of commercial street development across the country and Hangzhou works as an outstanding example. Commercial street economy is boosting China's urbanization and industry prosperity. Concerning on the rapid and sound development of commercial street in China, this paper introduces many problems and conflicts that block domestic commercial street development. With the guidances of China Commercial Walking Street Committee and Hangzhou Bureau of Economy and Trade, data analysis by Hangzhou Municipal Bureau of Statistics, and case study of commercial streets in Hangzhou, the paper states that commercial street development beyond China's socialism economic system should follow the guidance of scientific outlook on development, insist on government-led and market-driven, design first and service-oriented, and highlight core feature and comprehensive facility. Also, it is essential to unify and ensure legal status of management committee, and streamline organizational structure, balance between interest groups, weaken conflicts of public and private, and promote industry association development and privately-operated public affairs to ensure sustainable development of commercial street, which will truly benefit domestic urbanization as well as improve people's material and cultural life. For the other developing countries in the urgent progress of industrialization and urbanization, the paper is expected to be guidelines.
\end{abstract}

Keywords: commercial street, interests conflicts, public policy, Hangzhou, scientific outlook on development

\section{Introduction}

As the epitome and essence of urban business, commercial street is a multi-purpose, multi-industry type, and multi-format collection of business. The ancient means of commercial street in China may date back to the Tang Dynasty (Year 618-907 AC). Modern commercial street construction in China started from 1980s within modern means and traditional elements. The ancient and modern commercial streets mirror and highlight urban history, characters, properties, and life quality. China's urbanization has worldwide implications; noble-winning economist Joseph Eugene Stieglitz has once named urbanization in China and high-tech development in the United States as the two primary factors shaping the world of the 21st century (Retrieved from http://www.china.org.cn/top10/2013-03/12/content_28216370.htm). Recent years have witnessed the commercial street boom along with rapid progress of urbanization throughout China, which is particularly

HE Zheng-biao (Washington Ho), M.A., Assistant Researcher, Hangzhou Bureau of Economy and Trade; Secretary, Zhejiang Administration of Work Safety.

Correspondence concerning this article should be addressed to HE Zheng-biao, No. 77 Xixihexia Road, Hangzhou 310012, China. E-mail: washington0223@hotmail.com. 
notable in Hangzhou city. Hangzhou, known as UN-Habitat Scroll of Honor Award City, China's Best Commerce City, and China's Best Investment City, has already arrived at high levels of developed country in many aspects particularly with its per capita GDP (by household) reached to 86,642 Chinese National Dollar $(\mathrm{CND})^{1}$ in year 2010. According to average exchange rate then between CND and U.S. Dollar (USD), Hangzhou's per capita GDP was 12,797 USD. The whole city contained a total population of 6,833,800, total urban population of $4,294,400$, and total non-agricultural population of $3,544,800^{2}$. Among which urban population accounted for $62.84 \%$ of the total population and non-agricultural population accounted for $51.87 \%$. Meanwhile, Hangzhou's commercial street development is in the forefront of China, which had built 20 national famous commercial streets. According to the case study of Hangzhou city, analysis of current domestic commercial street constructing and managing strategies, it will benefit commercial street China and abroad.

\section{The Function of Commercial Street}

According to the statistics from commercial streets in recent years both at home and abroad, commercial street acts very irreplaceable role in regional industry development as the displaying and sales platform. In Volume 3 Chapter 4 of The Wealth of Nations, Adam smith analyzed how urban commercial activities promote society and economy development of rural areas. Recent studies of some economist prove that relationship between urbanization and socio-economic development is so close that restrict each other (Northam, 1975); and one nation's economy growth is deeply related to its urbanization quality (Henderson, 2010). In developed countries, commercial street is an important element of urban civilization and life quality. In Philadelphia, commercial street group formed a better livable "City Center District" and created a "clean, safe, attractive, and braw public environment” (Garvin, 2010). In China, the sum of annual turnover of commercial street group in some large cities accounts for more than 70\% of regional total retail sales of goods. In Hangzhou, commercial streets boost regional urbanization and industrialization. For example, Wulin Road Women Fashion Street's annual total retail sales of goods arrived at three billion CND, contributed more than 100 million CND taxation, and attracted the newly-graduated college students doing business and re-hired laid-off workers more than 6,000 people. The increasing prominent role of commercial street in promoting urban economic development and social stability comes more certain with the tax contributions rising, career employment offering, industry managing, and stimulate domestic demand to expand consumption. To apply the guidance of scientific outlook on development and meet the people's growing material and cultural needs, a city should build commercial street matching urban scale and economic development to invigorate local business and industry, and unite commerce, tourism, and culture as one to promote regional economic prosperity and social harmony.

\section{Basic Principles of Commercial Street Construction}

Modern commercial street generally contains diverse industries and commerce forms, distinctive commerce features, certain commerce structures, convenience transportation, super safeguards, and rational consumption. Since the beginning of the 21st century, Hangzhou commercial street group has gained positive interaction among commerce business, urban construction, and tourism development. According to the construction and management practices and experiences of the Hangzhou commercial street group, there are

\footnotetext{
${ }^{1}$ Hangzhou Municipal Bureau of Statistics, Hangzhou Bulletin of Economic and Social Development Statistics of 2010 (Retrieved from http://www.hzstats.gov.cn/web/ShowNews.aspx?id=DwGeRFDvlVg=).

2 Hangzhou Municipal Bureau of Statistics, Hangzhou Statistics Yearbook of 2010 (Retrieved from http://www.hzstats.gov.cn/web/tjnj/nj2010/02/nj_.htm).
} 
three basic principles that can be learned for domestic commercial streets.

\section{Government-Led and Market-Driven}

Commercial street construction and management should rely on both the government's visible hand and the invisible hand of the market. American scholar Alexander Garvin stated that most of urbanization projects on pedestrian streets are results of close cooperation between business groups and local government, both of which are essential because local government is in charge of public resources, and the business groups provide transformation funds that required (Garvin, 2010). As a developing country, China's modernization (urbanization) requires government lead by centralized politics from macroscopic approach. In detail, commercial street construction is a systematic project involving building protection, facilities construction, store decoration and running, environment maintaining, etc.. It is totally different from any single simple urban construction project. The government's leading role is necessary especial in planning and layout, industries adjustment and reform, public service, supervision and inspection, and many other aspects. Commercial streets in Hangzhou are all built and managed beyond government-led and market-driven. Hangzhou set up an official "Commercial Street Planning and Construction Team" to guide the planning and construction of all commercial streets. And each commercial street set up its own "Management Committee" to be responsible for management and construction. Local government also drafted and carried out many positive policies and succeed hosting “The Sixth China Commercial Street Development Forum” in Hangzhou. Also the government gathered popularity and business opportunities to promote sound and rapid development of commercial streets by improving urban life quality and enhancing comprehensive resources to hold commercial expo and festivals.

On the other hand, commercial street should run by the market after government's construction is done. Commercial street originated from the development of commercial economy in ancient urban areas. Alexander Garvin told us that pedestrian street cannot attract market when there is none; the project of pedestrian street may be possible only if there are enough potential retail consumers gathered and there can provide new facilities to attract plenty customers (Garvin, 2010). Businesses in commercial street, either running by government agents or private owners, are market behaviors and should be regulated by market. And free competition among enterprises inside commercial street is the result of natural selection by the market. So is the free competition between different commercial streets. While "the most effective way to prevent competition is usually getting the government involved” (Miller, Benjamin, \& North, 2005), which will definitely weaken or even block the function of the market. Currently, market mechanism plays the fundamental role in the allocation of resources under the conditions of China's socialist market economy. The operation of construction and management of commercial street must respect market mechanism. Hangzhou, with its thriving industry and mature market mechanism, has strongly ensured the market-based commercial street development. The local government always adhere to market-oriented system and carry on suitable regulation in the progress of commercial street development to guarantee market mechanism of fair play and free competition.

\section{Highlight Core Feature and Comprehensive Facility}

Commercial street construction should better balance between the core feature and comprehensive facility of the entire commercial block. On one hand, every commercial street should have its own core feature. Commercial street without core feature cannot survive in serious competition nowadays. In order to form unique feature for each commercial street, it is very essential that government should run the commercial street, rely on regional industries, history and cultural heritages, and mix these characters into modern business. As to 
create specific overall images of commercial street which involve logo system, facade colors, outdoor advertisements, urban furniture, night lighting, etc., government should make different styles to avoid homogeneous among regional commercial streets. Hangzhou, known as China's main producing area of silk and women fashion as well as the ancient capital of Southern Song Dynasty, here government seized these unique features and finally built three national famous commercial street as China Silk Town, Wulin Road Women Fashion Street, and Southern Song Imperial Street, which not only promote local character industries prosperity, but also succeed avoiding homogenization among commercial streets in Hangzhou.

On the other hand, government should fully improve the comprehensive facility of commercial street, because commercial street is born as the special comprehensive urban district. It is necessary to build comprehensive commercial sites which are related to diet, shelter, leisure, shopping, transportation, entertainment, etc. through overall planning and design to meet the diverse demands of citizens and tourist. It is also essential to mix commercial business and cultural tourism into urban facilities and public services. Only by these means can commercial street gain popular gathering and business opportunities to maintain its vigor and vitality. Data from Wulin Road Women Fashion Street show that the main industry of women fashion shops account for about $70 \%$, the ancillary industries of women leisure and entertainment shops account for about $20 \%$, the other related industries such as food, finance, gardening, telecom, etc. account for about $10 \%$. The main industry well matched the comprehensive complement due to the management committee's adjustment and program of whole merchant station's structures. Commercial streets, as the unique tourism complex, greatly promote business and tourism in Hangzhou. According to data from the Hangzhou Bureau of Statistics, Hangzhou had received 2,757,100 foreign tourists and 63,048,900 domestic visitors in year 2010, with total tourism revenue reached to 102,570 million $\mathrm{CND}^{3}$. As the special tourism resources, commercial streets have made tremendous contributions to it.

\section{Design First and Service-Oriented}

Commercial street construction must beyond detail and careful design based on the overall situation of the commercial block, which aims to ensure scientific development. It is important to fully research and investigate, plan and design overall image, spatial layout, transportation system, public facilities, advertisement, lighting, industrial development, and brand management solution regarding to its function, economy, society, culture, and ecology. In detail, the most popular shops should be set in "the golden ratio" areas of commercial street. Research twice of locals' purchase rate and tourist consumption level before constructing, and build commercial buildings with rich external room and multi-functional internal operating spaces which contain diverse industries. Combine with commerce, tourism, and culture together to operate multi-industry businesses and adhere to sound and rapid development and take care of both social and economic benefit, blind construction without systemic design will cause serious risks. Alexander Garvin told a case. In San Monica (U.S.), the city hall spent 10 years building up an advanced shopping center with band arcade and air-conditions. The new shopping center attracted plenty of customers from The Third Street when it opened. As a result, the city hall had to spend 10 years attracting customers back to The Third Street (Garvin, 2010). In the year 2008 and 2009, Hangzhou Administration of Urban Design, China Academy of Art and Management Committee of Wulin Road Women Fashion Street made the first domestic design system of commercial

\footnotetext{
${ }^{3}$ Hangzhou Municipal Bureau of Statistics, Hangzhou Bulletin of Economic and Social Development Statistics of 2010 (Retrieved from http://www.hzstats.gov.cn/web/ShowNews.aspx?id=DwGeRFDvlVg=).
} 
street-“Hangzhou Commercial Block Design (Wulin Road)”. The design can be an authoritative guiding book on construction of commercial street with its overall layout consist of economy, culture, society, ecology, and civilization, which inherit the theme "Better City, Better Life" of World Expo 2010 Shanghai. Recently, commercial street construction in Hangzhou focused on promoting economic and social development in old city. As Richard Florida stated, those abandoned buildings, garages, workshops, and urban blocks, which carry industry civilization and represent the city's industry history, may become gathering places for contemporary artists, and resuscitate the old declining city due to the cultural and creative industry prosperity (Florida, 2004). Since 2010, North Zhongshan Road Creative Street, known as Hangzhou's Akihabara ${ }^{4}$, utilized buildings abandoned by some removed stated-owned enterprises in old city. Most buildings were transformed into "Creative Park" and have attracted over 100 cultural and creative enterprises and 40 designer studios to settle down.

Meanwhile, the managers of commercial street must firmly establish the concept of serving the enterprises. China had a long time history of anti-mechanism and judged commerce with negative outlook. Autocracy as illiberal feudalism and illogical communism had seriously blocked the development of free market until reform and opening up in 1978. Besides keeping clean and order, government managers of commercial street should combine management together with service, implement all of regional preferential policies related to banking, taxation, and investment, offer free housework, business training, information consultation, etc. to help enterprises keep aspiring and competitive. As to marketing solution, government should make innovative ways to enlarge and strengthen regional market. For instance, it is widely and deeply benefit when government organize relative festivals for local enterprises or help them to join in, and vigorously promote the membership spending, online trading, online payment and other means of marketing, advance development by promoting from simple commodity trading into selling services, concepts, design, and brand along with a scientific and reasonable increased value of the commodity. By these means can government improve the comprehensive competitiveness of enterprises.

\section{Problems and Countermeasures}

Unlike commercial street of developed countries, China's modern commercial street was born with many Chinese characteristics which are remarkable in the way how and how much government intervene in. With the rapid development of China's industrialization and urbanization in recent decades, Hangzhou has arranged a remarkable commercial street boom. There are certainly many problems that need to be further resolved. To follow the guidance of scientific outlook on development, it is never too late to forge ahead of time and create scientific solutions to ensure sound development on commercial street.

\section{Unifying and Ensuring Legal Status}

Government administration of commercial street in China usually named management committee. Though as official managing institution, management committee do not really exist in government administration system, nor is there any supportive unified legal system. According to the brief introduction of Tiananmen District Management Committee from its official website, it is a detached office of Beijing municipal government, administer governmental authority and duty, manage public security, environmental hygiene,

\footnotetext{
${ }^{4}$ Akihabara, located in Tokyo, Japan, is a major shopping area for electronic, computer, anime, games, and otaku goods, including new and used items (Retrieved from http://en.wikipedia.org/wiki/Akihabara).
} 
industry and commerce, commodity price, taxation, etc. of Tiananmen area with the cooperation of relevant government departments, overall manage regional commerce, services, transportation, etc. ${ }^{5}$

The same duty as Tiananmen District Management Committee, most of management committees of commercial streets are less authorized, which make management committee weak in the progress of commercial street construction and management. For example, management committee of Wulin Road Women Fashion Street of Hangzhou is a national institution and cannot be respected as government or its detached office although management committee overall constructs, reforms, and manages the commercial street. The issue is becoming worse that authority cannot match duty. Plus, current legislation system and governmental regulation are still uncertain of management models, organizational principles and forms of commercial street. Domestic management committees of commercial streets vary from being strengthened to weaken. Some local governments even rescind management committee. Considering the sound development of commercial street and urban commerce, it is urgent to carry out legislative work national wide. The first solution is to ensure management committee of commercial street as certain government agency or detached office, and define suitable authority with duty. The second one is to transform advanced experiences and innovative initiatives that management committee gained into routine work measures as regulation forms.

\section{Streamlining Organizational Structure}

The management committee of commercial street is mainly responsible for economic works in commercial block such as operating real estate, attracting investment, serving enterprises and general taxation. With the expansion of urbanization, increasing population, and serious demand of social stability, management committees have to take many more social work to keep clean, order, and security. Plus, bureaucratism and formalism have doubled daily meetings, documents, inspections, and examinations, let alone the Party's routine work. All these make most of the management committees burden too much and dilute its main duty of economic work. Actually, the issue is not whether the management committee is too big or too small, but whether it works — whether it promotes regional industrialization and urbanization.

Accordingly, the organizational structure and running mechanism of the management committee should adhere to "small agency, big service" and be more effective. It is better to make chief leader both in charge of the Party and the administration, unit commercial streets nearby as one entire group to ensure one management committee in charge of several commercial streets, and shrink irrelevant departments and managers. It has also benefit to handle some difficult social work and trivial public affairs to industry associations and relative agencies. Among commercial streets in Hangzhou, Wulin Road Women Fashion Street and North Zhongshan Road Creative Street share the same management committee, which greatly shrink irrelevant departments and managers, but it still works well.

\section{Balance Between Interest Group}

The more economic activities government undertakes in commercial street, the more conflicts of interest there will be among different interest groups. Many interest groups directly affect commercial street, which especial are the territorial administration, management committee, and its affiliated state-owned company.

On the one hand, it is important to keep a balance between management committee and territorial township (or city district) administration. The two relative official departments of Hangzhou municipal government are in the same level of administration system and tangle on commercial street, but the authority,

\footnotetext{
${ }^{5}$ Management Committee of Tiananmen Square District (Retrieved from http://www.tiananmen.org.cn/).
} 
duty, and benefit of each side always counteract. Some authors argue that "individuals have interests that conflict” (G. Brennan \& J. M. Buchanan, 1985). In fact, government administration and its staff will be as selfish as ordinary people in the market. Particularly when management committee takes over all economic business of the commercial street while territorial administration burdens most of social works there. It is hard to carry on effective bilateral cooperation if each side just sees in its own interests. Therefore, it is important to make it clear what management committee does and what territorial administration does by confining each side's rights, duties, and profits. Currently, management committee is primarily responsible for economic development which concerns on planning, construction, investment, regulatory, service and coordination, and territorial administration handles social work to keep order, clean, and safe of commercial street. The higher government should establish a fair and reasonable appraising system which consists of not only management committee but also territorial government. When the higher government rewards management committee's economy contribution, it should also consider of local government's devotement and offer suitable rewards.

On the other hand, it is essential to harmonize management committee and its affiliated state-owned company. In the beginning of commercial street's construction, management committee should set up its own state-owned company to be responsible for detail operations, and keep the company in order and efficient. This way is conducive to concentrate all resources on construction and make up official rules and regulations' limitation to management committee which cannot do business as private agent. After construction is done, it is better to separate the state-owned company from management committee, which should perform management functions as the purely market runner when the commercial street is enough mature. By this mean can the commercial street be commercially managed by the company, and can the company fully integrate resources and regulate operation to enhance the operation. Above all, the company has to accept the leadership of the management committee, and receive the guidance of the relevant governmental departments to ensure sound development.

\section{Weakening Conflicts of Public and Private}

Some European scholars advocated the cooperation of government and private owners in the process of urban reconstruction, and government expects to harvest overall economic benefits while private owners gain profits relying on local labor and market; the cooperation can create new employment, offer training, social services and facilities, and support local enterprises ${ }^{6}$. China's traditional legal ideologies always put public interests first and detracted private interests. Newly decades of highly centralized political and economic system before reform and opening up made the situation worse. Obviously, "private and differentially identifiable interest is relevant at all to human behavior” (G. Brennan \& J. M. Buchanan, 1985). The contradiction between socialized producing and private ownership of the means of production gradually heated in the progress of commercial street boom based on socialist market economy. It is difficult for the management committee to handle over the syndrome especial in some old urban commercial blocks. Some Chinese experts recognized that the old city usually attracted numerous businessmen, corporations, individuals, and local government to compete here because of its favorable location advantage and huge inherent economic value (Zhang, 2010).

Nowadays, it is not easy to unify diverse property rights into single state-owned form. When it comes to

6 Geddes, M. (2006). Local partnership: a successful strategy for social cohesion (Retrieved from http://www.eurofound.europa.eu/publications/htmlfiles/ef9816.htm). 
housing property, the owners of private property rights always pursuit of highest rental, and never consider of the renter's survive who rents the house doing business. These are so harmful to the sustainable development of commercial street and result in serious crisis. In Hangzhou, some private owners of commercial streets often drive up rent and force many small special shops withdraw from there, which gradually devalues the whole commercial block. Generally, it is urgent that government should innovate new methods to resolve or at least weaken conflicts between public and private. As to diverse housing property especial to unenlightened private owners, it is essential for the management committee to control most of housing property and transform all destructive private properties into national or collective ownership by means of purchase, exchange, or migration.

\section{Privatization of Public Affairs}

Public affairs are the last bastion of the planned economy. Public goods and services can be provided through the market by the private sector, also can be provided directly by government departments, or subsidies given by government departments through the market. Some American scholars find out that the average cost of services that public sector provided is $35 \%-95 \%$ higher than that private contractor offered (Osborne \& Gaebler, 1996). The commercial block is an open society that contains urban furniture maintenance, environment conservation, citizen education, and many other utilities. And management committee always be in charge of public affairs as a monopoly. Therefore, privatizing public affairs and bringing in outsourcing are the inevitable choice to ensure quality and efficiency of public goods and services.

For most of the management committee, it will be beneficial to transfer or partly transfer public affairs to private ownership individuals and industry associates. It will bring in market competition mechanism and rely on private institutions to meet the needs of the public. Privatization of commercial street's public affairs can effectively improve the efficiency and save certain capital. Newly-constructed commercial streets in Hangzhou all privately-operate public affairs and bring in outsourcing to pursuit high effect during construction, which turn out not only efficient but also save remarkable capital than many other commercial streets.

\section{Promoting Industry Associations}

As the third sector and intermediary organization, industry association serves government and enterprises. In developed countries, industry association beyond market economy is much more mature and multi-functional, which plays an important role in keeping order and fair competition in the market, reducing transaction costs between operators, protecting legitimate rights and interests of the market players, improving decision-making and management of the market, and making united regulation for industries and enterprises. Above all, industry association can support and help enterprises especial during economic crisis and recession.

The modern means of industry association were founded late in China. Industry association related to commercial streets has not reached its desired effects. It is difficult to integrate a strong cohesion and combat effectiveness. However, industry associations in Hangzhou are booming commercial streets group economic prosperity due to their systemic, sound, pragmatic, and united. Since the international financial crisis of year 2008, Hangzhou's industry associations and commercial streets group united as one to overcome the difficulties and minimize the impact of the crisis. As a result, it is very essential to cultivate a system of mature industry associations and make the most of them. So far, industry associations can be helpful for commercial street in market development, information sharing, recession warning, industry self-regulation, product certification, brand maintenance, etc.. Also management committee can hand most of commercial street's public affairs to 
some mature industry associations by outsourcing.

\section{Conclusions}

Commercial street greatly meets the serious demands of population, lands, resources, and industries concentrated in developed eastern urban areas of China. According to "the top 100 commodity trading markets of year 2007", it shows that over 90\% best markets concentrated in the eastern coastal provinces of China (China General Chamber of Commerce, 2008). With the deeply implement of national strategies of "Western Development" and "The Rise of Central Region" as well as the transformation of economic growth pattern of export-oriented into domestic demand-led, China's central and western regions will gain remarkable development due to the vast inland market. Thus, the commercial street boom will gradually extend to the central and western regions and re-promote regional economic and social development.

However, commercial street development in China must rely on regional economic and social development, and avoid the blind commercial street boom. It is widely important to follow the guidance of scientific outlook on development, insist on government-led and market-driven, design first and service-oriented, and highlight core feature and comprehensive facility. Also, it is essential to unify and ensure legal status of management committee, and streamline the organizational structure, balance between interest group, weaken conflicts of public and private, and promote industry association development and privatization of public affairs to ensure sustainable and sound development of commercial street.

Moreover, China's commercial street development can be good lectures for most developing countries. As to BRICKS (Brazil, the Russian Federation, India, China, and South Africa) countries which have vast landscape, huge population, and hurry on the progress of industrialization and urbanization as China, it is multi-functional to construct well-matched commercial streets in the worldwide recession by means of working for food and promote harmonious development of society and the economy.

\section{References}

Brennan, G., \& Buchanan, J. M. (1985). The reason of rulers: Constitutional political economy (pp. 51-52). New York: Cambridge University Press.

China General Chamber of Commerce. (2008). 2008 almanac of China's commerce (p. 438). Beijing: China Commerce Yearbook Press.

Florida, R. (2004). The flight of the creative class (pp. 37-41). New York: Harper Collins Publisher Inc..

Garvin, A. (2010). The American city: What works what does not (pp. 150-191). In Y. Huang (Ed.). Beijing: China Architecture \& Building Press.

Henderson, J. V. (2010). Cities and development. Journal of Regional Science, 50(1), 515-540.

Miller, R. L., Benjamin, D. K., \& North, D. C. (2005). The economics of public issues (p. 123). San Antonio: Pearson Education, Inc..

Northam, R. M. (1975). Urban geography. New York: John Wiley \& Sons.

Osborne, D., \& Gaebler, T. (1996). Reinventing government (p. 59). Shanghai: Shanghai Translation Publishing House.

Zhang, J. (2010). From paradox to innovation: Study of old city renewing beyond property right system (p. 3). Beijing: China Architecture \& Building Press. 